\title{
Association of polymorphisms in forkhead box C2 and perilipin genes with bone mineral density in community-dwelling Japanese individuals
}

\author{
YOSHIJI YAMADA ${ }^{1}$, FUJIKO ANDO ${ }^{2}$ and HIROSHI SHIMOKATA ${ }^{2}$ \\ ${ }^{1}$ Department of Human Functional Genomics, Life Science Research Center, Mie University, Tsu, Mie; \\ ${ }^{2}$ Department of Epidemiology, National Institute for Longevity Sciences, Obu, Aichi, Japan
}

Received January 16, 2006; Accepted March 22, 2006

\begin{abstract}
Evidence suggests the existence of a close relation between lipid metabolism and bone remodeling. We hypothesized that polymorphisms of genes that play a role in lipid metabolism, such as those for forkhead box C2 (FOXC2) and perilipin $(P L I N)$, might affect bone mineral density (BMD). We thus examined the possible relationships between a $-512 \mathrm{C} \rightarrow \mathrm{T}$ polymorphism of FOXC2 and a $1243 \mathrm{C} \rightarrow \mathrm{T}$ polymorphism of PLIN to BMD in communitydwelling Japanese women and men. The subjects (1129 men, 1114 women for FOXC2; 1122 men, 1112 women for PLIN) were aged 40 to 79 years and were randomly recruited to a population-based prospective cohort study of aging and agerelated diseases in Japan. Genotypes for FOXC2 and PLIN were determined with a fluorescence-based allele-specific DNA primer assay system. The $-512 \mathrm{C} \rightarrow \mathrm{T}$ polymorphism of FOXC2 was associated with BMD for the distal and proximal radius in men and in premenopausal women as well as with BMD for the distal radius and total body in postmenopausal women, with the $\mathrm{T}$ allele being related to reduced BMD. The $1243 \mathrm{C} \rightarrow \mathrm{T}$ polymorphism of PLIN was associated with BMD for the total body, lumbar spine, femoral neck, and trochanter in men, with the $\mathrm{C}$ allele being related to reduced BMD. This polymorphism of PLIN was not associated with BMD in all women. These results suggest that FOXC2 is a susceptibility locus for reduced BMD in Japanese men and women, and that PLIN constitutes such a locus in Japanese men.
\end{abstract}

\section{Introduction}

Osteoporosis, a major health problem of the elderly, is characterized by a reduction in bone mineral density (BMD) and a

Correspondence to: Dr Yoshiji Yamada, Department of Human Functional Genomics, Life Science Research Center, Mie University, 1577 Kurima-machiya, Tsu, Mie 514-8507, Japan

E-mail: yamada@gene.mie-u.ac.jp

Key words: polymorphism, genetics, osteoporosis, bone density, forkhead box $\mathrm{C} 2$, perilipin deterioration in the microarchitecture of bone, both of which result in predisposition to fractures (1). Although reproductive, nutritional, and lifestyle factors influence BMD, family and twin studies have suggested that BMD is largely heritable and under the control of multiple genes (2-4). Personalized prevention of osteoporosis and osteoporotic fractures is an important public health goal, one approach to which is to identify disease susceptibility genes. Although genetic linkage analyses (5-7) and candidate gene association studies (7-10) have implicated various loci and genes in predisposition to osteoporosis or fractures, the genes that confer susceptibility to this disease remain to be identified definitively. In addition, because of ethnic differences in gene polymorphisms as well as in lifestyle and environmental factors, it is important to examine polymorphisms related to BMD in each ethnic group.

Bone loss is associated with an expansion of adipose tissue in bone marrow (11), and osteoblasts and adipocytes share a common progenitor derived from stromal cells in bone marrow (12). Products of lipoprotein oxidation and an atherogenic diet also inhibit preosteoblast differentiation and result in reduced bone mineralization $(12,13)$. In addition, lipid-lowering agents (statins) stimulate bone formation and inhibit bone resorption, resulting in the prevention of both bone loss and osteoporotic fractures (14). Early postmenopausal women with an atherogenic serum lipid profile were found to have a lower BMD for the lumbar spine or femoral neck and an increased risk of osteopenia compared with those with a normal lipid profile (15). Postmenopausal women with increased plasma concentrations of low density lipoprotein (LDL) cholesterol have also been shown to be at greater risk of developing osteopenia than are those with normal concentrations, suggesting that an increased plasma level of LDL-cholesterol is a risk factor for reduced BMD (16). These observations suggest the existence of a close relationship between lipid metabolism and bone remodeling as well as demonstrating adverse effects of an atherogenic lipid profile on the latter. We thus hypothesized that polymorphisms of genes that play a role in lipid metabolism, such as those for forkhead box $\mathrm{C} 2$ (FOXC2) and perilipin $(P L I N)$, might affect BMD.

$F O X C 2$, a forkhead-winged helix transcription factor, is a key regulator of adipocyte metabolism (17). Transgenic mice that overexpress $F O X C 2$ specifically in white and brown adipocytes manifest a lean and insulin-sensitive phenotype. 
In these mice, deposition of white adipose tissue in the abdomen is reduced, with such tissue also exhibiting a brown fat-like histology, whereas interscapular brown adipose tissue is hypertrophic. Increased expression of FOXC2 in adipocytes had pleiotropic effects on the expression of genes important in cellular differentiation and metabolism, insulin action, adrenergic sensitivity, and intracellular signaling. These various FOXC2-dependent changes appeared to confer protection against obesity. Furthermore, increased FOXC2 expression induced by a high-fat diet in wild-type mice seems to counteract most of the signs associated with obesity, including hypertriglyceridemia and diet-induced insulin resistance, suggesting that this gene might also protect against type 2 diabetes (17). These findings suggest that FOXC2 is a candidate gene for predisposition to obesity and type 2 diabetes mellitus, and that it may also play a role in bone remodeling.

Perilipins are a family of proteins that coat intracellular lipid droplets. Expression of PLIN is largely restricted to adipocytes and steroidogenic cells $(18,19)$, and it appears to function primarily in the regulation of intracellular lipolysis in adipocytes $(20,21)$. Perilipin promotes cellular storage of triglycerides by reducing the rate of triglyceride hydrolysis, and it also controls the release of triglycerides when requried. The absence of PLIN confers a lean phenotype and counterbalances both genetic and diet-induced obesity in mice $(22,23)$. In contrast, increased expression of PLIN correlates with increased adiposity in humans (24). PLIN is thus implicated as a candidate gene for human obesity, and it may therefore also affect bone remodeling.

We have been attempting to identify gene polymorphisms that are significantly associated with BMD in Japanese women or men in a population-based study. In the present study, we examined the relationship with polymorphisms of FOXC2 and PLIN to BMD, even though there is no apparent biological link between these genes. Our aim was to identify a single polymorphism significantly associated with BMD for each gene. Among several polymorphisms previously identified, the $-512 \mathrm{C} \rightarrow \mathrm{T}$ polymorphism of FOXC2 and the $1243 \mathrm{C} \rightarrow \mathrm{T}$ polymorphism of PLIN have been shown to potentially affect gene function $(25,26)$. We thus examined the relations of these polymorphisms to BMD in Japanese women and men in our population-based cohort.

\section{Materials and methods}

Study population. The National Institute for Longevity Sciences-Longitudinal Study of Aging is a population-based prospective cohort study of aging and age-related diseases (27). The subjects are stratified by both age and sex, and are randomly selected from resident registrations in the city of Obu and town of Higashiura in central Japan $(28,29)$. The lifestyle of residents in this area is typical of that of Japanese individuals. The numbers of men and women recruited were similar and ages at the baseline were 40 to 79 years, with similar numbers of participants in each decade $(40 \mathrm{~s}, 50 \mathrm{~s}, 60 \mathrm{~s}$, 70 s). The subjects were followed up every 2 years. All participants were subjected at a special center to a detailed examination, which included not only medical evaluation but also assessment of exercise physiology, body composition, nutrition, and psychology. Individuals with disorders known to cause abnormalities of bone metabolism, including diabetes mellitus, chronic renal failure, rheumatoid arthritis, as well as thyroid, parathyroid, adrenal, and other endocrine diseases, or those who had taken drugs that affect bone metabolism, such as estrogen, glucocorticoids, bisphosphonates, vitamin D, and statins, were excluded from the present study. Individuals whose genotypes were not successfully determined (nine individuals for $P L I N$ ) were also excluded from the analysis.

We examined the relationship of BMD at various sites to the $-512 \mathrm{C} \rightarrow \mathrm{T}$ polymorphism of FOXC2 (NCBI, Y08223, nt685) in 2243 individuals (1129 men, 1114 women) and to the $1243 \mathrm{C} \rightarrow \mathrm{T}$ polymorphism of PLIN (NCBI, dbSNP, rs2304796) in 2234 individuals (1122 men and 1112 women). In addition, to uncover potential differences between women according to menopausal status, we conducted all analyses separately for premenopausal and postmenopausal women. Menopausal status was evaluated with a detailed questionnaire, and menopause was defined as complete cessation of menstruation. The study protocol complies with the Declaration of Helsinki and was approved by the Committee on Ethics of Human Research of the National Institute for Longevity Sciences. Written informed consent was obtained from each subject.

Measurement of BMD. BMD at the radius was measured by peripheral quantitative computed tomography (pQCT) (Desiscan 1000; Scanco Medical, Bassersdorf, Switzerland) and was expressed as D50 (BMD for the inner 50\% of the cross-sectional area of the distal radius, comprising mostly cancellous bone), D100 (BMD for the entire cross-sectional area of the distal radius, including both cancellous and cortical bone), and P100 (BMD for the entire cross-sectional area of the proximal radius, consisting mostly of cortical bone). BMD for the total body, lumbar spine (L2-L4), right femoral neck, and right trochanter was measured by dual-energy X-ray absorptiometry (DXA) (QDR 4500; Hologic, Bedford, MA). The coefficients of variation of the pQCT instrument for BMD values were $0.7 \%$ (D50), $1.0 \%$ (D100), and 0.6\% (P100), and those of the DXA instrument were $0.9 \%$ (total body), $0.9 \%$ (L2-L4), $1.3 \%$ (femoral neck), and $1.0 \%$ (trochanter).

Determination of genotype. Genotypes for FOXC2 and PLIN were determined with a fluorescence-based allele-specific DNA primer assay system (Toyobo Gene Analysis, Tsuruga, Japan) (30). The polymorphic region of FOXC2 was amplified by the polymerase chain reaction with sense primers labeled at the $5^{\prime}$ end with either fluorescein isothiocyanate (5'-AACT CGCTTTCAGCAAGAAGXㅡㄴ-3') or Texas red (5'-ACTC GCTTTCAGCAAGAAGXTT-3') and with an antisense primer labeled at the 5' end with biotin (5'-AGGCCAAGTCC CTTTTAGGGA-3'). The polymorphic region of PLIN was amplified with allele-specific sense primers labeled at the $5^{\prime}$ end with either fluorescein isothiocyanate (5'-CCTCCСCTT GGTTGAGGX $\left.\underline{G A}-3^{\prime}\right)$ or Texas red (5'-GCCCTCCCC TTGGTTGAGGXAA-3') and with an antisense primer labeled at the 5 ' end with biotin (5'-AGGGAGGGTGC TGCACCTCAC-3'). The reaction mixture $(25 \mu \mathrm{l})$ contained $20 \mathrm{ng}$ of DNA, $5 \mathrm{pmol}$ of each primer, $0.2 \mathrm{mmol} / \mathrm{l}$ of each deoxynucleoside triphosphate, 4 (for FOXC2) or 3.5 (for PLIN) $\mathrm{mmol} / \mathrm{l} \mathrm{MgCl}_{2}$, and $1 \mathrm{U}$ of rTaq DNA polymerase (Toyobo, Osaka, Japan) in polymerase buffer. The ampli- 
Table I. BMD and other characteristics for all men $(\mathrm{n}=1129)$ according to FOXC2 genotype. ${ }^{\mathrm{a}}$

\begin{tabular}{lrrrr}
\hline Characteristic & CC & CT & TT & CT+TT \\
\hline Number (\%) & $543(48.1)$ & $468(41.5)$ & $118(10.5)$ & $586(51.90$ \\
Age (years) & $59.4 \pm 0.5$ & $58.8 \pm 0.5$ & $60.0 \pm 1.0$ & $59.0 \pm 0.5$ \\
Height (cm) & $164.6 \pm 0.3$ & $164.6 \pm 0.3$ & $164.6 \pm 0.6$ & $164.6 \pm 0.3$ \\
Body weight $(\mathrm{kg})$ & $62.8 \pm 0.4$ & $61.9 \pm 0.4$ & $63.1 \pm 0.8$ & $62.1 \pm 0.4$ \\
BMD measured with pQCT $\left(\mathrm{mg} / \mathrm{cm}^{3}\right)$ & & & & \\
D50 & $273.0 \pm 2.8$ & $262.5 \pm 3.1^{\mathrm{b}}$ & $254.4 \pm 6.1^{\mathrm{c}}$ & $260.8 \pm 2.7^{\mathrm{d}}$ \\
D100 & $548.3 \pm 3.9$ & $536.3 \pm 4.2$ & $524.7 \pm 8.5^{\mathrm{e}}$ & $533.9 \pm 3.8^{\mathrm{f}}$ \\
P100 & $1194.7 \pm 6.0$ & $1176.5 \pm 6.5$ & $1175.7 \pm 12.9$ & $1176.3 \pm 5.8^{\mathrm{g}}$ \\
BMD measured with DXA $\left(\mathrm{g} / \mathrm{cm}^{2}\right)$ & & & $1.086 \pm 0.008$ & $1.085 \pm 0.004$ \\
Total body & $1.090 \pm 0.004$ & $1.085 \pm 0.004$ & $0.989 \pm 0.014$ & $0.977 \pm 0.006$ \\
L2-L4 & $0.989 \pm 0.006$ & $0.974 \pm 0.007$ & $0.743 \pm 0.009$ & $0.753 \pm 0.004$ \\
Femoral neck & $0.753 \pm 0.004$ & $0.756 \pm 0.005$ & $0.667 \pm 0.009$ & $0.667 \pm 0.004$ \\
Trochanter & $0.669 \pm 0.004$ & $0.668 \pm 0.004$ & & \\
\hline
\end{tabular}

${ }^{\mathrm{a}} \mathrm{BMD}$ is adjusted for age, height, and body weight. Data are means $\pm \mathrm{SE} .{ }^{\mathrm{b}} \mathrm{P}=0.0307,{ }^{\mathrm{c}} \mathrm{P}=0.0158,{ }^{\mathrm{d}} \mathrm{P}=0.0020,{ }^{\mathrm{e}} \mathrm{P}=0.0306,{ }^{\mathrm{f}} \mathrm{P}=0.0084$, ${ }^{\mathrm{g}} \mathrm{P}=0.0270$ versus $\mathrm{CC}$.

fication protocol comprised initial denaturation at $95^{\circ} \mathrm{C}$ for $5 \mathrm{~min} ; 35$ cycles of denaturation at $95^{\circ} \mathrm{C}$ for $30 \mathrm{sec}$, annealing at $60^{\circ} \mathrm{C}$ (for $F O X C 2$ ) or $67.5^{\circ} \mathrm{C}$ (for PLIN) for $30 \mathrm{sec}$, and extension at $72^{\circ} \mathrm{C}$ for $30 \mathrm{sec}$; and a final extension at $72^{\circ} \mathrm{C}$ for $2 \mathrm{~min}$. The amplified DNA was then incubated in a solution containing streptavidin-conjugated magnetic beads in the wells of a 96-well plate at room temperature, and the plate was placed on a magnetic stand. The supernatants from each well were transferred to the wells of a 96-well plate containing $0.01 \mathrm{~mol} / \mathrm{l} \mathrm{NaOH}$ and were measured for fluorescence with a microplate reader (Fluoroscan Ascent; Dainippon Pharmaceutical, Osaka, Japan) at excitation and emission wavelengths of 485 and $538 \mathrm{~nm}$, respectively, for fluorescein isothiocyanate and of 584 and $612 \mathrm{~nm}$, respectively, for Texas red.

Statistical analysis. Statistical analysis was performed with SAS software (SAS Institute, Cary, NC). Data were compared among three genotype groups by one-way analysis of variance and the Tukey-Kramer post hoc test, and between two groups (dominant or recessive model) by the unpaired Student's t- test. BMD values were compared among genotypes for each polymorphism with adjustment for age, height, and body weight by the least squares method in a general linear model. Allele frequencies were estimated by the gene-counting method, and the chi-square test was used to identify significant departure from Hardy-Weinberg equilibrium. The effect of genotype for each polymorphism on BMD was evaluated by single regression analysis; $\mathrm{P}$ values and $\mathrm{R}^{2}$ were calculated from analysis of genotype for $F O X C 2(\mathrm{CC}=0, \mathrm{CT}=\mathrm{TT}=1$ for men; $\mathrm{CC}=\mathrm{CT}=0, \mathrm{TT}=1$ for women $)$ or $P \operatorname{LIN}(\mathrm{CC}=\mathrm{CT}=0$, $\mathrm{TT}=1)$. A $\mathrm{P}$ value of $<0.05$ was considered statistically significant.

\section{Results}

Relationship between the $-512 C \rightarrow T$ polymorphism of FOXC2 and BMD. The distribution of $-512 \mathrm{C} \rightarrow \mathrm{T}$ genotypes of $F O X C 2$ was in Hardy-Weinberg equilibrium, and age, height, and body weight did not differ among genotypes, for all men (Table I). Among all men, BMD for D50, with adjustment for age, height, and body weight, was greater in individuals with the CC genotype than in those with the CT genotype, the TT genotype, or in the combined group of CT and TT genotypes (Table I). BMD for D100 was greater in individuals with the CC genotype than in those with the TT genotype or in the combined group of CT and TT genotypes. BMD for P100 was also greater in individuals with the $\mathrm{CC}$ genotype than in the combined group of CT and TT genotypes. The differences in BMD for D50 and D100 between individuals with the $\mathrm{CC}$ genotype and those with the TT genotype (expressed as a percentage of the larger value) were 6.8 and $4.3 \%$, respectively. The difference in BMD for P100 between individuals with the CC genotype and the combined group of CT and TT genotypes was $1.5 \%$.

The distribution of $-512 \mathrm{C} \rightarrow \mathrm{T}$ genotypes of FOXC2 was in Hardy-Weinberg equilibrium, and age, height, and body weight did not differ among genotypes, for all women (Table II). Among all women, BMD for D50, with adjustment for age, height, and body weight, was greater in the combined group of CC and CT genotypes than in individuals with the TT genotype (Table II). BMD for D100 was greater in individuals with the $\mathrm{CC}$ genotype, in individuals with the CT genotype, or in the combined group of CC and CT genotypes than in those with the TT genotype. BMD for the total body was also greater in the combined group of CC and CT genotypes than in individuals with the TT genotype. The differences in BMD for 
Table II. BMD and other characteristics for all women $(\mathrm{n}=1114)$ according to FOXC2 genotype. ${ }^{\mathrm{a}}$

\begin{tabular}{|c|c|c|c|c|}
\hline Characteristic & $\mathrm{CC}$ & $\mathrm{CT}$ & TT & $\mathrm{CC}+\mathrm{CT}$ \\
\hline Number $(\%)$ & $525(47.1)$ & $479(43.0)$ & $110(9.9)$ & $1004(90.1)$ \\
\hline Age (years) & $59.2 \pm 0.5$ & $59.4 \pm 0.5$ & $59.1 \pm 1.0$ & $59.3 \pm 0.3$ \\
\hline Height $(\mathrm{cm})$ & $151.5 \pm 0.3$ & $151.1 \pm 0.3$ & $151.8 \pm 0.6$ & $151.3 \pm 0.2$ \\
\hline Body weight $(\mathrm{kg})$ & $52.5 \pm 0.4$ & $52.6 \pm 0.4$ & $52.7 \pm 0.8$ & $52.6 \pm 0.3$ \\
\hline \multicolumn{5}{|c|}{ BMD measured with pQCT $\left(\mathrm{mg} / \mathrm{cm}^{3}\right)$} \\
\hline D50 & $187.2 \pm 2.7$ & $185.9 \pm 2.8$ & $172.8 \pm 6.0$ & $186.6 \pm 1.9^{b}$ \\
\hline D100 & $487.5 \pm 3.9^{c}$ & $489.2 \pm 4.1^{\mathrm{d}}$ & $463.2 \pm 8.6$ & $488.3 \pm 2.8^{\mathrm{e}}$ \\
\hline $\mathrm{P} 100$ & $1156.6 \pm 6.3$ & $1156.4 \pm 6.6$ & $1130.3 \pm 13.9$ & $1156.5 \pm 4.5$ \\
\hline \multicolumn{5}{|c|}{ BMD measured with DXA $\left(\mathrm{g} / \mathrm{cm}^{2}\right)$} \\
\hline Total body & $0.967 \pm 0.004$ & $0.968 \pm 0.004$ & $0.948 \pm 0.008$ & $0.968 \pm 0.003^{\mathrm{f}}$ \\
\hline L2-L4 & $0.869 \pm 0.006$ & $0.866 \pm 0.006$ & $0.854 \pm 0.012$ & $0.867 \pm 0.004$ \\
\hline Femoral neck & $0.680 \pm 0.004$ & $0.679 \pm 0.004$ & $0.666 \pm 0.008$ & $0.679 \pm 0.003$ \\
\hline Trochanter & $0.574 \pm 0.004$ & $0.570 \pm 0.004$ & $0.560 \pm 0.008$ & $0.572 \pm 0.003$ \\
\hline
\end{tabular}

${ }^{\mathrm{a}} \mathrm{BMD}$ is adjusted for age, height, and body weight. Data are means $\pm \mathrm{SE}{ }^{\mathrm{b}} \mathrm{P}=0.0284,{ }^{\mathrm{c}} \mathrm{P}=0.0275,{ }^{\mathrm{d}} \mathrm{P}=0.0174,{ }^{\mathrm{e}} \mathrm{P}=0.0056,{ }^{\mathrm{f}} \mathrm{P}=0.0200$ versus TT.

Table III. BMD and other characteristics for premenopausal women (n=281) according to FOXC2 genotype. ${ }^{\mathrm{a}}$

\begin{tabular}{|c|c|c|c|c|}
\hline Characteristic & $\mathrm{CC}$ & $\mathrm{CT}$ & TT & $\mathrm{CT}+\mathrm{TT}$ \\
\hline Number $(\%)$ & $132(47.0)$ & $122(43.4)$ & $27(9.6)$ & $254(90.4)$ \\
\hline Age (years) & $45.7 \pm 0.4$ & $46.9 \pm 0.4$ & $45.1 \pm 0.9$ & $46.3 \pm 0.3$ \\
\hline Height $(\mathrm{cm})$ & $155.7 \pm 0.4^{\mathrm{b}}$ & $153.4 \pm 0.4$ & $153.7 \pm 0.9$ & $154.6 \pm 0.3$ \\
\hline Body weight (kg) & $54.4 \pm 0.7$ & $54.4 \pm 0.7$ & $53.9 \pm 1.6$ & $54.4 \pm 0.5$ \\
\hline \multicolumn{5}{|c|}{ BMD measured with pQCT $\left(\mathrm{mg} / \mathrm{cm}^{3}\right)$} \\
\hline D50 & $248.3 \pm 4.9$ & $244.1 \pm 5.1$ & $236.6 \pm 10.8$ & $246.3 \pm 3.5$ \\
\hline D100 & $614.0 \pm 6.8^{c}$ & $603.0 \pm 7.1$ & $571.6 \pm 15.2$ & $608.8 \pm 4.8^{\mathrm{d}}$ \\
\hline $\mathrm{P} 100$ & $1374.7 \pm 10.1^{\mathrm{e}}$ & $1354.7 \pm 10.6$ & $1315.3 \pm 22.6$ & $1365.1 \pm 7.2^{f}$ \\
\hline \multicolumn{5}{|c|}{ BMD measured with DXA $\left(\mathrm{g} / \mathrm{cm}^{2}\right)$} \\
\hline Total body & $1.098 \pm 0.007$ & $1.093 \pm 0.007$ & $1.073 \pm 0.016$ & $1.095 \pm 0.005$ \\
\hline L2-L4 & $1.032 \pm 0.010$ & $1.018 \pm 0.010$ & $1.020 \pm 0.022$ & $1.025 \pm 0.007$ \\
\hline Femoral neck & $0.772 \pm 0.008$ & $0.770 \pm 0.008$ & $0.773 \pm 0.017$ & $0.771 \pm 0.006$ \\
\hline Trochanter & $0.662 \pm 0.007$ & $0.655 \pm 0.008$ & $0.643 \pm 0.016$ & $0.659 \pm 0.005$ \\
\hline
\end{tabular}

${ }^{\mathrm{a} B M D}$ is adjusted for age, height and body weight. Data are means $\pm \mathrm{SE} .{ }^{\mathrm{b}} \mathrm{P}=0.0004$ versus $\mathrm{CT}$; ${ }^{\mathrm{c}} \mathrm{P}=0.0308,{ }^{\mathrm{d}} \mathrm{P}=0.0209,{ }^{\mathrm{e}} \mathrm{P}=0.0448$, ${ }^{\mathrm{f}} \mathrm{P}=0.0368$ versus $\mathrm{TT}$.

D50, D100, and total body between the combined group of $\mathrm{CC}$ and $\mathrm{CT}$ genotypes and individuals with the TT genotype were $7.4,5.1$, and $2.1 \%$, respectively.
To examine the possible influence of menopause on the relationship between FOXC2 genotype and BMD, we analyzed premenopausal and postmenopausal women independently. 
Table IV. BMD and other characteristics for postmenopausal women $(\mathrm{n}=816)$ according to $F O X C 2$ genotype. $^{\mathrm{a}}$

\begin{tabular}{|c|c|c|c|c|}
\hline Characteristic & $\mathrm{CC}$ & CT & $\mathrm{TT}$ & $\mathrm{CT}+\mathrm{TT}$ \\
\hline Number $(\%)$ & $384(47.1)$ & $352(43.1)$ & $80(9.8)$ & $736(90.2)$ \\
\hline Age (years) & $64.0 \pm 0.4$ & $63.8 \pm 0.5$ & $64.1 \pm 1.0$ & $63.9 \pm 0.3$ \\
\hline Height $(\mathrm{cm})$ & $150.0 \pm 0.3$ & $150.2 \pm 0.3$ & $151.0 \pm 0.7$ & $150.1 \pm 0.2$ \\
\hline Body weight (kg) & $51.9 \pm 0.4$ & $51.9 \pm 0.4$ & $52.4 \pm 0.9$ & $51.9 \pm 0.3$ \\
\hline \multicolumn{5}{|c|}{ BMD measured with pQCT $\left(\mathrm{mg} / \mathrm{cm}^{3}\right)$} \\
\hline D50 & $165.4 \pm 3.3$ & $164.9 \pm 3.4$ & $149.1 \pm 7.2$ & $165.2 \pm 2.3^{\mathrm{b}}$ \\
\hline D100 & $442.7 \pm 4.7$ & $447.0 \pm 4.8$ & $426.7 \pm 10.4$ & $444.8 \pm 3.4$ \\
\hline $\mathrm{P} 100$ & $1079.4 \pm 7.8$ & $1083.7 \pm 8.0$ & $1063.0 \pm 17.2$ & $1081.4 \pm 5.6$ \\
\hline \multicolumn{5}{|c|}{ BMD measured with DXA $\left(\mathrm{g} / \mathrm{cm}^{2}\right)$} \\
\hline Total body & $0.921 \pm 0.004$ & $0.922 \pm 0.005$ & $0.901 \pm 0.010$ & $0.92 \pm 0.003^{c}$ \\
\hline L2-L4 & $0.810 \pm 0.007$ & $0.811 \pm 0.007$ & $0.795 \pm 0.014$ & $0.810 \pm 0.005$ \\
\hline Femoral neck & $0.646 \pm 0.004$ & $0.645 \pm 0.004$ & $0.629 \pm 0.009$ & $0.646 \pm 0.003$ \\
\hline Trochanter & $0.543 \pm 0.004$ & $0.539 \pm 0.004$ & $0.531 \pm 0.009$ & $0.541 \pm 0.003$ \\
\hline
\end{tabular}

${ }^{a} \mathrm{BMD}$ is adjusted for age, height and body weight. Data are means $\pm \mathrm{SE} .{ }^{\mathrm{b}} \mathrm{P}=0.0342,{ }^{\mathrm{c}} \mathrm{P}=0.0492$ versus TT.

Table V. BMD and other characteristics for all men $(\mathrm{n}=1122)$ according to PLIN genotype. ${ }^{\mathrm{a}}$

\begin{tabular}{|c|c|c|c|c|}
\hline Characteristic & $\mathrm{CC}$ & CT & TT & $\mathrm{CC}+\mathrm{CT}$ \\
\hline Number (\%) & $630(56.1)$ & $418(37.3)$ & $74(6.6)$ & $1048(93.4)$ \\
\hline Age (years) & $58.9 \pm 0.4$ & $59.7 \pm 0.5$ & $59.0 \pm 1.3$ & $59.2 \pm 0.3$ \\
\hline Height (cm) & $164.7 \pm 0.3$ & $164.4 \pm 0.3$ & $164.8 \pm 0.7$ & $164.6 \pm 0.2$ \\
\hline Body weight $(\mathrm{kg})$ & $62.6 \pm 0.4$ & $62.5 \pm 0.4$ & $61.1 \pm 1.1$ & $62.6 \pm 0.3$ \\
\hline \multicolumn{5}{|c|}{ BMD measured with pQCT $\left(\mathrm{mg} / \mathrm{cm}^{3}\right)$} \\
\hline D50 & $265.2 \pm 2.7$ & $267.2 \pm 3.2$ & $276.1 \pm 7.7$ & $266.0 \pm 2.1$ \\
\hline D100 & $537.8 \pm 3.7$ & $542.6 \pm 4.5$ & $554.0 \pm 10.6$ & $539.7 \pm 2.8$ \\
\hline P100 & $1178.3 \pm 5.6$ & $1193.7 \pm 6.8$ & $1187.7 \pm 16.1$ & $1184.5 \pm 4.3$ \\
\hline \multicolumn{5}{|c|}{ BMD measured with DXA $\left(\mathrm{g} / \mathrm{cm}^{2}\right)$} \\
\hline Total body & $1.083 \pm 0.004$ & $1.090 \pm 0.004$ & $1.107 \pm 0.010$ & $1.086 \pm 0.003^{b}$ \\
\hline L2-L4 & $0.975 \pm 0.006$ & $0.988 \pm 0.007$ & $1.017 \pm 0.017$ & $0.980 \pm 0.005^{c}$ \\
\hline Femoral neck & $0.749 \pm 0.004^{\mathrm{d}, \mathrm{h}}$ & $0.752 \pm 0.005$ & $0.790 \pm 0.011$ & $0.750 \pm 0.003$ \\
\hline Trochanter & $0.663 \pm 0.004^{\mathrm{f}}$ & $0.671 \pm 0.005$ & $0.696 \pm 0.011$ & $0.666 \pm 0.003$ \\
\hline
\end{tabular}

${ }^{\mathrm{a}} \mathrm{BMD}$ is adjusted for age, height, and body weight. Data are mean $\pm \mathrm{SE} .{ }^{\mathrm{b}} \mathrm{P}=0.0461,{ }^{\mathrm{c}} \mathrm{P}=0.0396,{ }^{\mathrm{d}} \mathrm{P}=0.0021,{ }^{\mathrm{e}} \mathrm{P}=0.0007,{ }^{\mathrm{f}} \mathrm{P}=0.0140$, ${ }^{\mathrm{g}} \mathrm{P}=0.0106$ versus $\mathrm{TT} ;{ }^{\mathrm{h}} \mathrm{P}=0.0052$ versus $\mathrm{CT}$.

Because of their small number $(n=17)$, perimenopausal women were excluded from this analysis. The distribution of $-512 \mathrm{C} \rightarrow \mathrm{T}$ genotypes of FOXC2 was in Hardy-Weinberg equilibrium in premenopausal (Table III) and postmenopausal
(Table IV) women. Age and body weight did not differ among genotypes for premenopausal or postmenopausal women. Height was greater in premenopausal women with the CC genotype that in those with the CT genotype (Table III), but it 
Table VI. BMD and other characteristics for all women $(\mathrm{n}=1112)$ according to PLIN genotype. ${ }^{\mathrm{a}}$

\begin{tabular}{|c|c|c|c|c|}
\hline Characteristic & $\mathrm{CC}$ & $\mathrm{CT}$ & $\mathrm{TT}$ & $\mathrm{CC}+\mathrm{CT}$ \\
\hline Number $(\%)$ & $609(54.8)$ & $415(37.3)$ & $88(7.9)$ & $1024(92.1)$ \\
\hline Age (years) & $59.7 \pm 0.4$ & $58.8 \pm 0.5$ & $57.9 \pm 1.2$ & $59.4 \pm 0.3$ \\
\hline Height $(\mathrm{cm})$ & $151.3 \pm 0.2$ & $151.4 \pm 0.3$ & $151.8 \pm 0.6$ & $151.3 \pm 0.2$ \\
\hline Body weight (kg) & $52.3 \pm 0.3$ & $53.1 \pm 0.4$ & $52.7 \pm 0.9$ & $52.6 \pm 0.3$ \\
\hline \multicolumn{5}{|c|}{ BMD measured with pQCT $\left(\mathrm{mg} / \mathrm{cm}^{3}\right)$} \\
\hline D50 & $185.2 \pm 2.5$ & $186.3 \pm 3.0$ & $180.6 \pm 6.5$ & $185.7 \pm 1.9$ \\
\hline D100 & $483.4 \pm 3.6$ & $486.5 \pm 4.4$ & $497.9 \pm 9.5$ & $484.7 \pm 2.8$ \\
\hline $\mathrm{P} 100$ & $1151.2 \pm 5.9$ & $1154.4 \pm 7.1$ & $1168.2 \pm 15.3$ & $1152.5 \pm 4.5$ \\
\hline \multicolumn{5}{|c|}{ BMD measured with DXA $\left(\mathrm{g} / \mathrm{cm}^{2}\right)$} \\
\hline Total body & $0.966 \pm 0.003$ & $0.963 \pm 0.004$ & $0.968 \pm 0.009$ & $0.965 \pm 0.003$ \\
\hline L2-L4 & $0.864 \pm 0.005$ & $0.868 \pm 0.006$ & $0.863 \pm 0.014$ & $0.866 \pm 0.004$ \\
\hline Femoral neck & $0.680 \pm 0.003$ & $0.677 \pm 0.004$ & $0.672 \pm 0.009$ & $0.678 \pm 0.003$ \\
\hline Trochanter & $0.572 \pm 0.003$ & $0.572 \pm 0.004$ & $0.561 \pm 0.009$ & $0.572 \pm 0.003$ \\
\hline
\end{tabular}

${ }^{\text {aBMD }}$ is adjusted for age, height, and body weight. Data are means $\pm \mathrm{SE}$.

Table VII. Effects of genotypes for FOXC2 and PLIN on BMD.a

\begin{tabular}{|c|c|c|c|c|c|c|c|}
\hline Genotype & D50 & D100 & P100 & $\begin{array}{l}\text { Total } \\
\text { body }\end{array}$ & L2-L4 & $\begin{array}{c}\text { Femoral } \\
\text { neck }\end{array}$ & Trochanter \\
\hline \multicolumn{8}{|l|}{ Men } \\
\hline FOXC2 & $\mathbf{0 . 0 0 2 7}(0.0083)$ & $\mathbf{0 . 0 1 7 0}(0.0053)$ & 0.0661 & 0.3055 & 0.0787 & 0.7315 & 0.4283 \\
\hline PLIN & 0.2709 & 0.2305 & 0.7867 & 0.1800 & 0.2188 & $\mathbf{0 . 0 2 0 7}(0.0048)$ & 0.1239 \\
\hline \multicolumn{8}{|l|}{ All women } \\
\hline FOXC2 & 0.0780 & 0.0526 & 0.2333 & 0.1683 & 0.5003 & 0.2771 & 0.3362 \\
\hline PLIN & 0.8510 & 0.0566 & 0.0919 & 0.2873 & 0.6016 & 0.8517 & 0.8361 \\
\hline \multicolumn{8}{|c|}{ Premenopausal women } \\
\hline FOXC2 & 0.7208 & 0.1008 & 0.2751 & 0.2353 & 0.8690 & 0.8614 & 0.4129 \\
\hline PLIN & 0.1660 & 0.8853 & 0.8262 & 0.9462 & 0.6911 & 0.1224 & 0.1015 \\
\hline \multicolumn{8}{|c|}{ Postmenopausal women } \\
\hline FOXC2 & $\mathbf{0 . 0 3 7 2}(0.0055)$ & 0.0947 & 0.2346 & 0.1393 & 0.4126 & 0.1810 & 0.4181 \\
\hline PLIN & 0.9305 & 0.2306 & 0.4186 & 0.7807 & 0.8573 & 0.7448 & 0.8836 \\
\hline
\end{tabular}

${ }^{a}$ Data were analyzed by single regression analysis of genotype for $F O X C 2(\mathrm{CC}=0, \mathrm{CT}=\mathrm{TT}=1$ for men; $\mathrm{CC}=\mathrm{CT}=0$, TT=1 for women $)$ or $P \operatorname{LIN}(\mathrm{CC}=\mathrm{CT}=0, \mathrm{TT}=1)$. Data are $\mathrm{P}$ values $\left(R^{2}\right)$. $\mathrm{P}$ values of $<0.05$ are shown in bold.

did not differ among genotypes for postmenopausal women (Table IV). For premenopausal women, BMD for D100 or $\mathrm{P} 100$ was greater in individuals with the $\mathrm{CC}$ genotype or in the combined group of CC and CT genotypes than in subjects with the TT genotype (Table III). The differences in BMD for
D100 and P100 between individuals with the CC genotype and those with the TT genotype were 6.9 and $4.3 \%$, respectively. For postmenopausal women, BMD for D50 or the total body was greater in the combined group of CC and CT genotypes than in individuals with the TT genotype (Table IV). 
The differences in BMD for D50 and the total body between the combined group of CC and CT genotypes and individuals with the TT genotype were 9.7 and $2.2 \%$, respectively.

Relationsip between the $1243 C \rightarrow$ T polymorphism of PLIN and BMD. The distribution of $1243 \mathrm{C} \rightarrow \mathrm{T}$ genotypes of PLIN was in Hardy-Weinberg equilibrium, and age, height, and body weight did not differ among genotypes, for all men (Table V). Among all men, BMD for the total body or lumbar spine, with adjustment for age, height, and body weight, was significantly greater in individuals with the TT genotype than in the combined group of CC and CT genotypes (Table V). $\mathrm{BMD}$ for the femoral neck or trochanter was greater in individuals with the TT genotype than in those with the CC genotype or in the combined group of $\mathrm{CC}$ and $\mathrm{CT}$ genotypes. BMD for the femoral neck was also greater in individuals with the CT genotype than in those with the CC genotype. The differences in BMD for the total body and lumbar spine between individuals with the TT genotype and the combined group of CC and CT genotypes were 1.9 and $3.6 \%$, respectively. The differences in BMD for the femoral neck and trochanter between individuals with the TT genotype and those with the CC genotype were 5.2 and $4.7 \%$, respectively.

There was no significant relationship between PLIN genotype and BMD for all women (Table VI). For premenopausal women, BMD for D100 was greater in the combined group of TT and CT genotypes than in individuals with the CC genotype (data not shown). For postmenopausal women, no relationship was detected between PLIN genotype and BMD (data not shown).

Effects of genotypes for FOXC2 and PLIN on BMD. The effects of $-512 \mathrm{C} \rightarrow \mathrm{T}$ genotype for FOXC2 and $1243 \mathrm{C} \rightarrow \mathrm{T}$ genotype for PLIN on BMD at various sites were evaluated by single regression analysis (Table VII). This analysis revealed that $-512 \mathrm{C} \rightarrow \mathrm{T}$ genotype for FOXC2 affected BMD for D50 and D100 in men and BMD for D50 in postmenopausal women, and that $1243 \mathrm{C} \rightarrow \mathrm{T}$ genotype for PLIN affected BMD for the femoral neck in men.

\section{Discussion}

We have examined the relationship of the $-512 \mathrm{C} \rightarrow \mathrm{T}$ polymorphism of FOXC2 and the $1243 \mathrm{C} \rightarrow \mathrm{T}$ polymorphism of PLIN with BMD at various sites in community-dwelling Japanese women and men. Our results show that the T allele of FOXC2 is associated with reduced BMD in both men and women, and that the $\mathrm{C}$ allele of PLIN is associated with this condition in men.

Association of the $-512 C \rightarrow T$ polymorphism of FOXC2 with $B M D$. FOXC2-deficient mice show multiple defects of skeletal tissue. In the craniofacial skeleton of these animals, for example, the supraoccipital bone is missing and other bones are reduced in size $(31,32)$. FOXC2 is expressed in the early stage of chondrogenic differentiation both in vivo and in vitro, and bone morphogenetic proteins regulate $F O X C 2$ expression in skeletal precursor cells (33). Expression of FOXC2 in mesenchymal condensation and subsequently in cartilaginous tissue, as well as the phenotype of FOXC2-deficient mice, indicate that $F O X C 2$ contributes to the proliferation and differentiation of skeletal cells.

The $\mathrm{T}$ allele of the $-512 \mathrm{C} \rightarrow \mathrm{T}$ polymorphism in the $5^{\prime}$ untranslated region of FOXC2 was shown to be associated with enhanced insulin sensitivity and lower plasma triglyceride concentration in women (25). A higher level of expression of FOXC2 in visceral fat than in subcutaneous fat was also apparent only in individuals homozygous for the $\mathrm{T}$ allele. These observations suggest that increased expression of FOXC2 may protect against insulin resistance, and that the $-512 \mathrm{C} \rightarrow \mathrm{T}$ polymorphism of this gene may influence insulin sensitivity (25). We have now shown that this polymorphism of FOXC2 is associated with BMD in men and women, with the $\mathrm{T}$ allele being related to reduced bone mass. The mechanism responsible for the association of the $\mathrm{T}$ allele both with enhanced insulin sensitivity and lower plasma triglyceride concentrations in women (25) and with reduced bone mass in men and women (the present study) remains to be elucidated. The molecular mechanism of the effect of this polymorphism on bone remodeling also remains unclear.

Association of the $1243 C \rightarrow$ T polymorphism of PLIN with $B M D$. The AA genotype of the $11,482 \mathrm{G} \rightarrow \mathrm{A}$ polymorphism of PLIN (rs894160) was shown to be associated with a decreased PLIN content and increased lipolytic activity in adipocytes of women (34). Individuals with the $11,482 \mathrm{~A}$ variant of PLIN were also found to manifest both a lower baseline body weight and resistance to weight loss in response to a low-energy diet (35). Haplotypes of several polymorphisms of PLIN have been related to the risk of obesity, but the extent of this relationship differs between men and women (36) and among ethnic groups (37). The $1243 \mathrm{C} \rightarrow \mathrm{T}$ polymorphism of PLIN was associated with total cholesterol levels in Chinese (26). Men with the $1243 \mathrm{~T}$ variant (CT or TT genotype) had higher plasma concentrations of total cholesterol, high density lipoprotein (HDL)-cholesterol, and LDL-cholesterol than did male CC homozygotes, suggesting that the $1243 \mathrm{C} \rightarrow \mathrm{T}$ polymorphism of PLIN may affect lipid metabolism. Our present results show that the $1243 \mathrm{C} \rightarrow \mathrm{T}$ polymorphism of PLIN was associated with BMD in men, with the $\mathrm{C}$ allele being related to reduced bone mass. This polymorphism was not associated with body weight or body mass index (data not shown) in the present study, making it unlikely that its association with BMD in men was attributable to an effect on these parameters. The mechanism responsible for the association of the $\mathrm{C}$ allele with both lower plasma cholesterol concentrations in men (26) and reduced bone mass in men (the present study) remains to be elucidated. The effects of the $1243 \mathrm{C} \rightarrow \mathrm{T}$ polymorphism of PLIN on gene expression, the function of the encoded protein, or bone remodeling have not been determined.

Given the multiple comparisons of genotypes with BMD at various sites in the present study, it is not possible to exclude potential statistical errors such as false positives. It is also possible that the polymorphisms associated with reduced BMD in our study are in linkage disequilibrium with polymorphisms of other nearby genes that are actually responsible for the development of this condition. Furthermore, the relevance of the polymorphisms to gene transcription or to protein structure or function and their effects on bone remodeling were not 
determined in the present study. Despite these limitations, our present results suggest that FOXC2 is a susceptibility locus for reduced BMD in Japanese men and women and that PLIN constitutes such a locus in Japanese men. Determination of genotypes for these polymorphisms may prove informative for assessment of the genetic risk for reduced BMD.

\section{Acknowledgments}

Our research was supported in part by a research grant for Comprehensive Research on Aging and Health (H17-Chojyu039) from the Ministry of Health, Labor, and Welfare of Japan.

\section{References}

1. Kanis JA, Melton LJ III, Christiansen C, Johnston CC and Khaltaev N: The diagnosis of osteoporosis. J Bone Miner Res 9: 1137-1141, 1994.

2. Pocock NA, Eisman JA, Hopper JL, Yeates MG, Sambrook PN and Eberl S: Genetic determinations of bone mass in adults: a twin study. J Clin Invest 80: 706-710, 1987.

3. Gueguen R, Jouanny P, Guillemin F, Kuntz C, Pourel J and Siest G: Segregation analysis and variance components analysis of bone mineral density in healthy families. J Bone Miner Res 10: 2017-2022, 1995

4. Howard GM, Nguyen TV, Harris M, Kelly PJ and Eisman JA: Genetic and environmental contributions to the association between quantitative ultrasound and bone mineral density measurements: a twin study. J Bone Miner Res 13: 1318-1327, 1998.

5. Johnson ML, Gong G, Kimberling W, Recker SM, Kimmel DB and Recker RB: Linkage of a gene causing high bone mass to human chromosome 11 (11q12-13). Am J Hum Genet 60: 1326-1332, 1997.

6. Econs MJ, Koller DL, Hui SL, Fishburn T, Conneally PM, Johnston CC Jr, Peacock M and Foroud TM: Confirmation of linkage to chromosome $1 \mathrm{q}$ for peak vertebral bone mineral density in premenopausal white women. Am J Hum Genet 74: 223-228, 2004.

7. Morrison NA, Qi JC, Tokita A, Kelly PJ, Crofts L, Nguyen TV, Sambrook PN and Eisman JA: Prediction of bone density from vitamin D receptor alleles. Nature 367: 284-287, 1994.

8. Uitterlinden AG, Burger H, Huang Q, Yue F, McGuigan FEA, Grant SFA, Hofman A, van Leeuwen JPTM, Pols HAP and Ralston SH: Relation of alleles of the collagen type I $\alpha 1$ gene to bone density and the risk of osteoporotic fractures in postmenopausal women. N Engl J Med 338: 1016-1021, 1998.

9. Yamada Y, Ando F, Niino N and Shimokata H: Transforming growth factor- $\beta 1$ gene polymorphism and bone mineral density. JAMA 285: 167-168, 2001.

10. Ioannidis JP, Ralston SH, Bennett ST, Brandi ML, Grinberg D, Karassa FB, Langdahl B, van Meurs JB, Mosekilde L, Scollen S, Albagha OM, Bustamante M, Carey AH, Dunning AM, Enjuanes A, van Leeuwen JP, Mavilia C, Masi L, McGuigan FE, Nogues X, Pols HA, Reid DM, Schuit SC, Sherlock RE and Uitterlinden AG; GENOMOS Study: Differential genetic effects of ESR1 gene polymorphisms on osteoporosis outcomes. JAMA 292: 2105-2114, 2004

11. Bergman RJ, Gazit D, Kahn AJ, Gruber H, McDougall S and Hahn TJ: Age-related changes in osteogenic stem cells in mice. J Bone Miner Res 11: 568-577, 1996.

12. Parhami F, Jackson SM, Tintut Y, Le V, Balucan JP, Territo M and Demer LL: Atherogenic diet and minimally oxidized low density lipoprotein inhibit osteogenic and promote adipogenic differentiation of marrow stromal cells. J Bone Miner Res 14: 2067-2078, 1999.

13. Diascro DD Jr, Vogel RL, Johnson TE, Witherup KM, Pitzenberger SM, Rutledge SJ, Prescott DJ, Rodan GA and Schmidt A: High fatty acid content in rabbit serum is responsible for the differentiation of osteoblasts into adipocyte-like cells. J Bone Miner Res 13: 96-106, 1998.

14. McFarlane SI, Muniyappa R, Francisco R and Sowers JR: Clinical review 145: Pleiotropic effects of statins: lipid reduction and beyond. J Clin Endocrinol Metab 87: 1451-1458, 2002.
15. Orozco P: Atherogenic lipid profile and elevated lipoprotein (a) are associated with lower bone mineral density in early postmenopausal overweight women. Eur J Epidemiol 19: 1105-1112, 2004.

16. Poli A, Bruschi F, Cesana B, Rossi M, Paoletti R and Crosignani PG: Plasma low-density lipoprotein cholesterol and bone mass densitometry in postmenopausal women. Obstetr Gynecol 102: 922-926, 2003.

17. Cederberg A, Gronning LM, Ahren B, Tasken K, Carlsson P and Enerback S: FOXC2 is a winged helix gene that counteracts obesity, hypertriglyceridemia, and diet-induced insulin resistance. Cell 106: 563-573, 2001.

18. Greenberg AS, Egan JJ, Wek SA, Moos MC Jr, Londos C and Kimmel AR: Isolation of cDNAs for perilipins A and B: sequence and expression of lipid droplet-associated proteins of adipocytes. Proc Natl Acad Sci USA 90: 12035-12039, 1993.

19. Servetnick DA, Brasaemle DL, Gruia-Gray J, Servetnick DA, Schultz CJ, Levin DM and Kimmel AR: Perilipins are associated with cholesteryl ester droplets in steroidogenic adrenal cortical and Leydig cells. J Biol Chem 270: 16970-16973, 1995.

20. Souza SC, de Vargas LM, Yamamoto MT, Line P, Franciosa M, Moss L and Greenberg A: Overexpression of perilipin A and B blocks the ability of tumor necrosis factor alpha to increase lipolysis in 3T3-L1 adipocytes. J Biol Chem 273: 24665-24669, 1998.

21. Brasaemle DL, Rubin B, Harten IA, Gruia-Gray J, Kimmel A and Londos C: Perilipin A increases triacylglycerol storage by decreasing the rate of triacylglycerol hydrolysis. J Biol Chem 275: 38486-38493, 2000.

22. Martinez-Botas J, Anderson JB, Tessier D, Lapillojnne A, Hung-Junn Chang B, Quast M, Gorenstein D, Chen KH and Chan L: Absence of perilipin results in leanness and reverses obesity in Lepr (db/db) mice. Nat Genet 26: 474-479, 2000.

23. Tansey JT, Sztalryd C, Gruia-Gray J, Roush D, Zeo J, Gavrilova O, Reitman M, Deng CX, Ki C, Kimmel A and Londos C: Perilipin ablation results in a lean mouse with aberrant adipocyte lipolysis, enhanced leptin production, and resistance to diet-induced obesity. Proc Natl Acad Sci USA 98: 6494-6499, 2001.

24. Kern PA, Di Gregorio G, Lu T, Rassouli N and Ranganathan G: Perilipin expression in human adipose tissue is elevated with obesity. J Clin Endocrinol Metab 89: 1352-1358, 2004

25. Ridderstrale M, Carlsson E, Klannemark M, Cederberg A, Kosters C, Tornqvist H, Storgaard H, Vaag A, Enerback S and Groop L: FOXC2 mRNA expression and a 5' untranslated region polymorphism of the gene are associated with insulin resistance. Diabetes 51: 3554-3560, 2002.

26. Yan W, Chen S, Huang J, Shen Y, Qiang B and Gu D: Polymorphisms in PLIN and hypertension combined with obesity and lipid profiles in Han Chinese. Obes Res 12: 1733-1737, 2004.

27. Shimokata $\mathrm{H}$, Ando $\mathrm{F}$ and Niino N: A new comprehensive study on aging-the National Institute for Longevity Sciences, Longitudinal Study of Aging (NILS-LSA). J Epidemiol 10: S1-S9, 2000 .

28. Yamada Y, Ando F, Niino N and Shimokata H: Association of polymorphisms of interleukin-6, osteocalcin, and vitamin D receptor genes, alone or in combination, with bone mineral density in community-dwelling Japanese women and men. J Clin Endocrinol Metab 88: 3372-3378, 2003.

29. Yamada Y, Ando F, Niino N and Shimokata H: Association of polymorphisms of androgen receptor and klotho genes with bone mineral density in Japanese women. J Mol Med 83: 50-57, 2005.

30. Yamada Y, Izawa H, Ichihara S, Takatsu F, Ishihara H, Hirayama H, Sone T, Tanaka M and Yokota M: Prediction of the risk of myocardial infarction from polymorphisms in candidate genes. N Engl J Med 347: 1916-1923, 2002.

31. Winnier GE, Hargett L and Hogan BL: The winged helix transcription factor MFH1 is required for proliferation and patterning of paraxial mesoderm in the mouse embryo. Genes Dev 11: 926-940, 1997.

32. Iida K, Koseki H, Kakinuma H, Kato N, Mizutani-Koseki Y, Ohuchi H, Yoshioka H, Noji S, Kawamura K, Kataoka Y, Ueno F, Taniguchi M, Yoshida N, Sugiyama T and Miura N: Essential roles of the winged helix transcription factor MFH-1 in aortic arch patterning and skeletogenesis. Development 124: 4627-4638, 1997.

33. Nifuji A, Miura N, Kato N, Kellermann O and Noda M: Bone morphogenetic protein regulation of forkhead/winged helix ZC1 and in skeletal precursor cells. J Bone Miner Res 16: 1765-1771, 2001. 
34. Mottagui-Tabar S, Ryden M, Lofgren P, Faulds G, Hoffstedt J, Brookes AJ, Andersson I and Arner P: Evidence for an important role of perilipin in the regulation of adipocyte lipolysis. Diabetologia 46: 789-797, 2003.

35. Corella D, Qi L, Sorli JV, Godoy D, Portoles O, Coltell O, Greenberg AS and Ordovas JM: Obese subjects carrying the $11482 \mathrm{G}>\mathrm{A}$ polymorphism at the perilipin locus are resistant to weight loss after dietary energy restriction. J Clin Endocrinol Metab 90: 5121-5126, 2005.
36. Qi L, Shen H, Larson I, Schaefer EJ, Greenberg AS, Tregouet DA, Corella D and Ordovas JM: Gender-specific association of a perilipin gene haplotype with obesity risk in a white population. Obes Res 12: 1758-1765, 2004.

37. Qi L, Tai ES, Tan CE, Shen H, Chew SK, Greenberg AS, Corella D and Ordovas JM: Intragenic linkage disequilibrium structure of the human perilipin gene (PLIN) and haplotype association with increased obesity risk in a multiethnic Asian population. J Mol Med 83: 448-456, 2005. 